\title{
Issues Related to Deep Brain Stimulation for Treatment-Refractory Tourette's Syndrome
}

\author{
Mauro Porta ${ }^{a}$ Domenico Sevello ${ }^{a}$ Marco Sassi ${ }^{a}$ Arianna Brambilla ${ }^{a}$ \\ Stefano Defendi ${ }^{a}$ Alberto Priori ${ }^{b}$ Mary Robertson ${ }^{c}$ \\ ${ }^{a}$ Tourette Centre and Functional Neurosurgery, Istituto Galeazzi IRCCS and ${ }^{b}$ Department of Neurophysiology, \\ Ospedale Policlinico IRCCS, Milan, Italy; ${ }^{C}$ Institute of Neurology and Department of Mental Health Sciences, \\ University College London, London, UK
}

\section{Key Words}

Deep brain stimulation $\cdot$ Neuroimaging $\cdot$ Tourette's

syndrome

\begin{abstract}
Deep brain stimulation (DBS) has been used in a small number of patients with Tourette's syndrome and results on tics and comorbidities have been promising. The choice of the DBS target appears to influence the effectiveness; preliminary studies and case reports suggest that certain target areas may be more effective than others in patients with specific symptoms and comorbidities. Clinical data on the effect of DBS on tics and behavioral symptoms support its use in patients with severe, refractory Tourette's syndrome, particularly in younger adults who have a greater severity and prevalence of tics and comorbidities, and are more likely to experience social impairment. Although DBS has shown potential as an 'add-on' therapy for Tourette's syndrome patients failing to show adequate improvement with conventional conservative treatments, several issues remain to be resolved, including patient selection, choice of target, and adverse effects. Successful DBS requires an experienced multidisciplinary team for the management of these com-
\end{abstract}

plex pre-, peri- and postoperative issues. Future studies should include establishment of consistent inclusion criteria and specific practical requirements for clinical trials, evaluation of the impact of DBS on non-tic symptoms and their influence on outcome, social impairment and quality of life, and the identification of optimum neurophysiologically based DBS targets for improved efficacy in specific patient subtypes.

Copyright $\odot 2009$ S. Karger AG, Basel

\section{Introduction}

Tourette's syndrome is a chronic, neurobehavioral disorder characterized by waxing and waning motor and phonic tics that persist for at least 12 months [Robertson and Baron-Cohen, 1998; Robertson, 2000; ICD-10, 1992; DSM-IV-TR, 2000]. Tics generally occur in episodes and are preceded by premonitory sensations in the majority of patients [Leckman, 2002]. As many as $90 \%$ of patients with Tourette's syndrome have comorbid psychiatric conditions such as obsessive compulsive behavior (OCB), attention deficit hyperactivity disorder (ADHD), and exhibit self-injurious behavior (SIB), depression and anxi-

\section{KARGER}

Fax +41613061234 E-Mail karger@karger.ch www.karger.com

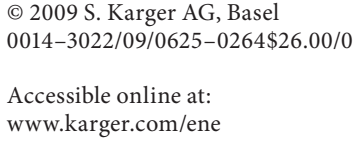

E-Maildr.sassi@yahoo.it 
ety [Robertson, 2000]; of these, OCB and ADHD are the most common, each occurring in up to $50 \%$ of patients [Mink et al., 2006].

Once thought to be relatively rare, the prevalence of Tourette's syndrome may in fact be as high as 50/10,000 in the general population [Leckman, 2002]. The condition is approximately 10 -fold more common in children than in adults [Leckman, 2002], with a prevalence of up to $299 / 10,000$ in 13- to 14 -year-old children [Mason et al., 1998]. In addition, Tourette's syndrome is approximately 3 times more common in males than females [Jankovic, 2001]. The onset of tics occurs at a mean age of 5-7 years [Freeman et al., 2000; Leckman, 2002], and severity appears to peak around the age of 10 years [Robertson, 2000; Leckman, 2002]. Symptoms may improve or even remit over time without treatment, and this tends to occur in the 3rd decade [Robertson, 2000; Leckman, 2002]. However, no patient or clinical characteristics predictive of spontaneous resolution have been found [Mink et al., 2006].

\section{Diagnosis and Classification}

Instruments used to diagnose Tourette's syndrome include the Diagnostic and Statistical Manual, 4th edition (DSM-IV) [DSM-IV-TR, 2000], the World Health Organization International Classification of Disease and Related Health Problems, 10th edition (ICD-10) [ICD-10, 1992] and the Tourette's Syndrome Classification Study Group (TSCSG) criteria [TSCS Group, 1993]. According to the TSCSG, a diagnosis of definite Tourette's syndrome requires motor and/or phonic tics to be witnessed by a reliable examiner or to be captured in a video recording [TSCS Group, 1993; Jankovic, 2001]. A patient may be considered to have Tourette's syndrome by history if a family member or close friend witnesses the tics and is able to provide a description to a reliable examiner that is accepted as indicative of Tourette's syndrome.

Motor tics are categorized as simple tonic (duration of $<100 \mathrm{~ms}$ ), dystonic (>300 ms) or clonic (>500 ms) tics, or complex tics which can appear to be purposeful or nonpurposeful [Jankovic, 1997]. Phonic tics are classified as simple (e.g. sniffing, throat clearing) or complex (e.g. echolalia, coprolalia or palilalia), and patients may exhibit compulsive tics. In the Robertson-Baron-Cohen classification system [Robertson and Baron-Cohen, 1998], the phenotype of the Tourette's syndrome is divided into three categories: simple Tourette's syndrome, which involves simple motor/phonic tics, full blown Tourette's syndrome, in which the patient has complex phonic tics, and Tourette's syndrome-plus, a term first coined by Packer [1997], where attention deficit disorders, OCB, SIB or nonobscene socially inappropriate behaviors are also present.

\section{Pathophysiology}

The underlying pathophysiology of Tourette's syndrome has yet to be fully elucidated [Jankovic, 2001]. However, functional magnetic resonance imaging studies in adults with Tourette's syndrome show that spontaneous tic expression and voluntary suppression of tics produce significantly different signal intensity in the basal ganglia and thalamus [Peterson et al., 1998]. This suggests that Tourette's syndrome may be caused by impaired modulation of a neural circuit involved in behavioral inhibition [Peterson et al., 1998; Jankovic, 2001]. The basal ganglia comprise a series of circuit loops projecting to specific nuclei involved in motor control, cognition, learning and emotion: the striatum (putamen, caudate nucleus, nucleus accumbens), the external and internal segments of the globus pallidus (GPi), the subthalamic nucleus and the substantia nigra. Disruption of one region of the loop also alters the function of its other components, and so no single location has been identified as the cause of Tourette's syndrome [Peterson et al., 1998]. The condition may be due to striatum abnormalities (neuroanatomic hypothesis), disinhibition of thalamic afferents or blockade of cortical inhibitions (neurophysiological hypothesis), or dopaminergic hypersensitivity, presynaptic abnormality or second mediator abnormality (neurochemical hypothesis) [Singer and Minzer, 2003].

\section{Management of Patients with Tourette's Syndrome}

Although it is not life-threatening, Tourette's syndrome can adversely influence the patients' quality of life, particularly with respect to social functioning, and may significantly impair their ability to perform everyday activities and their school or work performance [Leckman et al., 1998; Jankovic, 2001; Leckman, 2002]. Treatment may, therefore, be required, particularly when SIB, nonobscene socially inappropriate behaviors, anxiety, depression, $\mathrm{OCB}$ and $\mathrm{ADHD}$ are present.

Many patients with Tourette's syndrome can be managed with psychobehavioral therapy and education, for example habit reversal techniques, self-control or relaxation methods or a cognitive approach. However, phar- 
macological treatment may be required, particularly in patients with comorbidities. Pharmacological treatment options include the $\alpha_{2}$-adrenergics clonidine and guanfacine, typical and atypical neuroleptics such as haloperidol and risperidone, agents used to treat ADHD such as dopamine agonist stimulants and nonstimulant atomoxetine, tricyclic antidepressants, and selective serotonin reuptake inhibitors used in the treatment of OCB [Robertson, 2000; Leckman, 2002]. However, pharmacological treatments are all associated with side effects such as sedation and irritability with adrenergics, and sedation, dysphoria, weight gain and extrapyramidal symptoms with neuroleptic agents; such adverse effects can lead to poor adherence to medication regimens [Robertson, 2000; Leckman, 2002; Flaherty et al., 2005]. More aggressive, invasive interventions may be considered for patients unable to tolerate or resistant to previous pharmacological therapy [Flaherty et al., 2005]. Noninvasive transcranial magnetic stimulation has been studied in patients with Tourette's syndrome but has not been shown to be effective in alleviating tics [Orth et al., 2005].

\section{International Experience with Deep Brain Stimulation in Tourette's Syndrome}

Deep brain stimulation (DBS) is a reversible and adjustable neurosurgical technique involving the implantation of stimulating electrodes that send continuous electrical impulses to specific target areas in the brain. Following implantation of the electrodes, the stimulator settings are adjusted at follow-up endpoints to achieve optimal results with minimal adverse effects. DBS has been used successfully in patients with Parkinson's disease and other movement disorders [Benabid et al., 1998; Houeto et al., 2005; Vidailhet et al., 2005; Deuschl et al., 2006; Machado et al., 2006; Halpern et al., 2007]. In Parkinson's disease, DBS has shown long-term efficacy over periods of up to 11 years [Benabid et al., 1998; Krauss et al., 2001; Krack et al., 2003]. However, efficacy in other types of movement disorders has been variable in studies to date [Benabid et al., 1998].

DBS was first used for intractable Tourette's syndrome in 1999 [Vandewalle et al., 1999]. Although clinical studies of DBS in patients with Tourette's syndrome have involved very small numbers of patients to date, results have generally been favorable (table 1) [Vandewalle et al., 1999; Van der Linden et al., 2002; Visser-Vandewalle et al., 2003; Diederich et al., 2005; Flaherty et al., 2005; Houeto et al., 2005; Porta et al., 2005; Ackermans et al., 2006; Gallagher et al., 2006; Bajwa et al., 2007; Kuhn et al., 2007; Maciunas et al., 2007; Shahed et al., 2007; Dehning et al., 2008; Shields et al., 2008; Welter et al., 2008].

The objective of this paper was to review the clinical data and the issues surrounding the use of DBS, and to evaluate its feasibility and potential role in Tourette's syndrome. Pertinent published case reports, case series and clinical studies of DBS in patients with Tourette's syndrome were identified using the PubMed database and the key words Tourette/Tourette's syndrome, complications, tics and DBS.

\section{Review of the Issues on Deep Brain Stimulation in Tourette's Syndrome}

Although DBS has shown potential in the treatment of refractory Tourette's syndrome, there are numerous issues still to be resolved: (1) DBS proper indications and the definition of 'refractoriness' to conventional treatments, (2) the choice of target area on the basis of the clinical picture, (3) the suitability of general anesthesia DBS, (4) postoperative issues such as follow-up evaluation technique, and (5) optimization of pulse generator settings.

\section{Patient Selection}

Useful recommendations for patient selection have been provided by the Tourette Syndrome Association (TSA) [Mink et al., 2006]. However, on the basis of the waxing and waning nature of the clinical picture of Tourette's syndrome and considering the rather frequent behavioral comorbidities that limit patient's compliance, indication for DBS can be difficult. Moreover, the widespread orientation for DBS to be considered and adjunctive therapeutic maneuver over conservative or invasive/ nonsurgical treatments (such as botulinum toxin infiltration) is the most uncertain issue as criteria for the definition of 'refractoriness' are still not clearly defined.

Our group indicates DBS on the basis of a documented lack of response or presence of unbearable adverse effects over a minimum of 6 months' treatment with conventional (typical and atypical neuroleptics) and innovative treatment [including a dopamine depletor such as tetrabenazine, see Porta et al., 2008], while a selective serotonin reuptake inhibitor (fluvoxamine $25-100 \mathrm{mg}$ ) was also administered for obsessive-compulsive comorbidity, alone or in association with clorimipramine $25-100 \mathrm{mg} /$ day. ADHD was treated with clonidine $75-150 \mathrm{mg}$ /day or guanfacine $5 \mathrm{mg}$ or higher/day, while nonresponsive iso- 
Table 1. Published reports of DBS in the treatment of patients with Tourette's syndrome

\begin{tabular}{|c|c|c|c|c|c|c|}
\hline Reference & $\begin{array}{l}\text { Type of } \\
\text { study }\end{array}$ & $\begin{array}{l}\text { Length of } \\
\text { follow-up }\end{array}$ & Patients & $\begin{array}{l}\text { Target for } \\
\text { DBS }\end{array}$ & Efficacy & Adverse effects \\
\hline $\begin{array}{l}\text { Vandewalle et al., } \\
1999\end{array}$ & Case report & $\begin{array}{l}4 \text { months and } \\
1 \text { year }\end{array}$ & 1 & CM-Pf & $\begin{array}{l}70 \% \text { tic reduction at } 4 \text { months, tics abolished } \\
\text { at } 1 \text { year following adjustment of stimulator } \\
\text { settings }\end{array}$ & None reported \\
\hline $\begin{array}{l}\text { Van der Linden } \\
\text { et al., } 2002\end{array}$ & Case report & $\begin{array}{l}7 \text { days and } \\
6 \text { months }\end{array}$ & 1 & $\begin{array}{l}\text { GPi vs. } \\
\text { MT }\end{array}$ & $\begin{array}{l}\text { Tic reduction at } 7 \text { days: } 95 \text { vs. } 80 \% \text { with MT } \\
\text { Same at } 6 \text { months }\end{array}$ & None reported \\
\hline $\begin{array}{l}\text { Visser-Vandewalle } \\
\text { et al., } 2003\end{array}$ & Case report & $\begin{array}{l}5 \text { years, } \\
1 \text { year and } \\
8 \text { months }\end{array}$ & 3 & CM-Pf & Resolution of all major vocal and motor tics & $\begin{array}{l}\text { Sedation and changes in sexual } \\
\text { behavior } \\
\text { No serious adverse effects }\end{array}$ \\
\hline $\begin{array}{l}\text { Diederich et al., } \\
2005\end{array}$ & Case report & 14 months & 1 & GPi & Comorbidity, tic reduction $(70 \%)$ & $\begin{array}{l}\text { Pronation/supination } \\
\text { bradykinesia of the left } \\
\text { extremities }\end{array}$ \\
\hline $\begin{array}{l}\text { Flaherty et al., } \\
2005\end{array}$ & Case report & 18 months & 1 & IC & $25 \%$ improvement in YGTSS, comorbidity & None reported \\
\hline $\begin{array}{l}\text { Houeto et al., } \\
2005\end{array}$ & $\begin{array}{l}\text { Prospective, } \\
\text { DB, R }\end{array}$ & $\begin{array}{l}\text { Immediately } \\
\text { postsurgery, } \\
1 \text { and } \\
3 \text { months }\end{array}$ & 1 & $\begin{array}{l}\text { CM-Pf } \\
\text { and/or } \\
\text { GPi }\end{array}$ & $\begin{array}{l}\text { Improved tic severity by } 70 \% \text {, markedly } \\
\text { reduced coprolalia, and eliminated SIB } \\
\text { CM-Pf DBS resulted in less depression/more } \\
\text { emotionally stable than GPi } \\
\text { Tics and behavioral comorbidities } \\
\text { reappeared with 'sham' stimulation }\end{array}$ & Paraesthesia, weight loss \\
\hline Porta et al., 2005 & Case series & 6-14 months & 10 & $\begin{array}{l}\text { CM-Pf } \\
\text { VoA }\end{array}$ & $\begin{array}{l}\text { Tics, depression and compulsive behaviors } \\
\text { reduction, in } 2 \text { cases complete disappearance } \\
\text { of tics }\end{array}$ & $\begin{array}{l}\text { Deep vein thrombosis } \\
\text { intraprocedural psychomotor } \\
\text { agitation, wound diastasis }\end{array}$ \\
\hline $\begin{array}{l}\text { Ackermans et al., } \\
2006\end{array}$ & Case report & 1 year & 2 & $\begin{array}{l}\text { CM-Pf } \\
\text { and GPi }\end{array}$ & $\begin{array}{l}\text { Tic and compulsive behavior reduction with } \\
\text { both CM-Pf and GPi with pre-post } \\
\text { comparison and on-off test }\end{array}$ & No major side effects reported \\
\hline $\begin{array}{l}\text { Gallagher et al., } \\
2006\end{array}$ & Case report & Not stated & 1 & GPi & $\begin{array}{l}\text { Disappearance of vocal tics and marked } \\
\text { improvement in neck movements }\end{array}$ & None reported \\
\hline Shahed et al., 2007 & Case report & 4 months & 1 & GPi & $\begin{array}{l}\text { Markedly improved tic frequency and } \\
\text { severity, comorbidities, and quality of life }\end{array}$ & None reported \\
\hline Kuhn et al., 2007 & Case report & 2.5 years & 1 & NA & $\begin{array}{l}\text { Significant reduction in severity and } \\
\text { frequency of tics ( } 41 \% \text { YGTSS; } 50 \% \\
\text { MRVRS), coprolalia, OCD }\end{array}$ & None reported \\
\hline Bajwa et al., 2007 & Case report & 2 years & 1 & CM-Pf & $\begin{array}{l}\text { Substantial tic reduction ( } 95 \% \text { by self-report } \\
\text { and } 66 \% \text { by YGTSS) and resolution of } \\
\text { coprolalia } \\
\text { Improvement in OCD and mood }\end{array}$ & $\begin{array}{l}\text { Forceful motor tics remain, } \\
\text { deterioration of neurological } \\
\text { status }\end{array}$ \\
\hline Shields et al., 2008 & Case report & $\begin{array}{l}18 \text { months post- } \\
\text { internal capsule } \\
\text { DBS; } 3 \text { months } \\
\text { post-CM-Pf DBS }\end{array}$ & 1 & $\begin{array}{l}\text { IC followed } \\
\text { by CM-Pf } \\
\text { after } \\
18 \text { months }\end{array}$ & $\begin{array}{l}\text { Tic improvement and reduction in } \\
\text { psychiatric side effects with CM-Pf DBS vs. } \\
\text { internal capsule DBS }\end{array}$ & $\begin{array}{l}\text { Depressed mood and anxiety } \\
\text { side effects less with CM-Pf vs. } \\
\text { internal capsule DBS }\end{array}$ \\
\hline $\begin{array}{l}\text { Maciunas et al., } \\
2007\end{array}$ & $\begin{array}{l}\text { Prospective, } \\
\text { DB, R study }\end{array}$ & $\begin{array}{l}1(\mathrm{DB}) \text { and } 3 \\
\text { (open) months }\end{array}$ & 5 & CM-Pf & $\begin{array}{l}\text { Tic reduction (video and YGTSS) at } \\
1 \text { month, persistent at } 3 \text { months } \\
\text { Improvement in quality of life }\end{array}$ & None reported \\
\hline Welter et al., 2008 & $\begin{array}{l}\text { Prospective, } \\
\text { DB, R, } \\
\text { crossover } \\
\text { study }\end{array}$ & 2 months & 3 & $\begin{array}{l}\mathrm{CM}-\mathrm{Pf} \\
\text { and/or GPi }\end{array}$ & $\begin{array}{l}\text { Tic reduction: GPi: } 65,96 \text { and } 74 \% \text {; CM-Pf: } \\
64,30 \text { and } 40 \% \text {; CM-Pf/GPi: } 60,43 \text { and } 76 \%\end{array}$ & $\begin{array}{l}\text { Transient cheiro-oral or arm } \\
\text { paraesthesia (minutes), lethargy } \\
\text { (3-4 days), nausea, vertigo, } \\
\text { anxiety, libido decrease }\end{array}$ \\
\hline $\begin{array}{l}\text { Dehning et al., } \\
2008\end{array}$ & Case report & 12 months & 1 & GPi & Tic remission & None reported \\
\hline $\begin{array}{l}\text { Servello et al., } \\
2008\end{array}$ & Case series & 2-18 months & 18 & $\begin{array}{l}\text { CM-Pf VoA, } \\
\text { GPi and/or } \\
\text { NA }\end{array}$ & $\begin{array}{l}\text { Significant reduction in tics (YGTSS total } \\
\text { score and motor, phonic and social } \\
\text { impairment subscale scores) } \\
\text { Reductions in behavioral comorbidities and } \\
\text { premonitory sensations }\end{array}$ & $\begin{array}{l}\text { No serious permanent adverse } \\
\text { effects }\end{array}$ \\
\hline
\end{tabular}

DB = Double-blind; $\mathrm{IC}$ = internal capsule; $\mathrm{MT}$ = medial thalamus; $\mathrm{NA}=$ nucleus accumbens; $\mathrm{R}=$ randomized; OCD = obsessive-compulsive disorder. 
Table 2. Algorithm for the evaluation of indications for DBS: inclusion and exclusion criteria in use at our department

\begin{tabular}{lll}
\hline Features & Inclusion criteria & Exclusion criteria \\
\hline Diagnosis & Diagnosis made by trained personnel with DSM-IV-TR & DSM-IV-TR axis 1 major disease \\
\hline $\begin{array}{l}\text { Clinical } \\
\text { characteristics }\end{array}$ & $\begin{array}{l}\text { YGTSS } \geq 35 \text {, motor tic subscore } \geq 15 \\
\text { Tourette Syndrome causing SIB distress, harm } \\
\text { Compliant, able to provide informed consent }\end{array}$ & $\begin{array}{l}\text { Treatment-related or iatrogenic tic disorder } \\
\text { Suicide attempts } \\
\text { Cognitive dysfunction, dementia, or not compliant }\end{array}$ \\
$\begin{array}{l}\text { Therapeutic } \\
\text { issues }\end{array}$ & $\begin{array}{l}\text { Medical refractory after } 6 \text { months of adequate treatment for } \\
\text { tics and comorbid features }\end{array}$ & Substance abuse \\
\hline $\begin{array}{l}\text { Presurgical } \\
\text { evaluation }\end{array}$ & Judged able to withstand surgery after careful evaluation & $\begin{array}{l}\text { Previous brain surgery } \\
\text { Poor medical condition } \\
\text { Abnormal imaging examinations }\end{array}$ \\
\hline
\end{tabular}

lated tic manifestations were treated with botulinum toxin infiltration at the involved districts [including the crico-arythenoid muscles for phonic tics, Porta et al., 2003].

Patients were selected from our specialty clinic of thousands of Tourette's syndrome patients and all potential subjects were screened by a multidisciplinary team including a neurologist, neurosurgeon, neuropsychologist, psychiatrist, and ethicist, and were also required to have followed a psychobehavioral approach for at least 6 months without clinical success.

On the basis of our protocol, surgery should be considered if a patient continues to demonstrate clinical signs incompatible with normal social functioning, or reaching life-threatening evidence: in our study [Servello et al., 2008], 2 of the 18 patients underwent DBS because their refractory neck twisting tics caused cervical myelopathy requiring spinal surgery. Following DBS, the neck torsion bouts decreased significantly, motor impairment was stabilized and a motor rehabilitation program was established.

Moreover, in order to be eligible for DBS, patients should demonstrate compliance with previous treatments. Compliance should be assessed in terms of (1) adherence to pharmacological protocols, (2) completion of follow-up visits, and (3) adherence to psychobehavioral training programs (table 2).

Although the TSA states that DBS should not be administered in patients below the age of 25 years except in rare circumstances [Mink et al., 2006], there is only weak consensus regarding the minimum age at which DBS should be performed. Since spontaneous remission has been shown to occur in almost $50 \%$ of patients by the age of 18 years [Leckman, 2002] one could argue that treatment should be delayed to allow for the possibility of spontaneous remission in younger patients, whereas, on the other hand, an earlier, aggressive treatment could provide a better chance of improving the social capabilities of patients with severe social impairment caused by tics and comorbidities associated with Tourette's syndrome [Mink et al., 2006]. Although access to DBS should not be determined by age, a minimum age of 18 years is usually set for clinical study since, at this age, a patient can give legal consent to the DBS procedure. In our center, patients that undergo DBS tend to be older than 18 (mean age 30 years) because of the aforementioned possibility of spontaneous improvement. However, in one case DBS was performed at the age of 17 (with parental consent) due to a severe uninterrupted pattern of refractory tics that was described by our group as 'status ticcosus' because of its similarity with the crisis bursts of the epileptic patients in 'status epilepticus' [Servello et al., 2008].

Although tic severity and the patient's refractoriness to conventional therapies are the main criteria that determine the eligibility of patients for DBS, in our experience these parameters alone are not sufficient to define a good candidate for DBS. The adverse effects observed with DBS in Tourette's syndrome suggest that a thorough examination of the patient for proper assessment of deficits in somatic perception and emotional cognition (alexiti$\mathrm{mia}$ ) is necessary prior to DBS. Since Tourette's syndrome is characterized by impaired sensory and motor perception, somatic aspects should be considered and may aid in the identification of patients requiring special postoperative attention. Although there are no data available at present, the use of projective diagnostic tests such as the Machover Draw-a-Person test [Nogueira Rivero, 1960] might be considered important. This test allows to elucidate the self-perception and to evaluate how the subject perceives the parts of the body. The Premonitory Urges for Tic Scale (PUTS) [Woods et al., 2005] is a good instru- 
ment to assess the feeling and sensations experienced before the tic. These tests could help to identify subjects with somatophobia, hypochondria or somatization: these subjects may require closer monitoring after DBS. In addition, it is not clear whether the presumed etiology of Tourette's syndrome affects the response to DBS, as it is conceivable that cases arising from environmental factors may differ from those with a prominent hereditary influence.

\section{Target Choice}

A 'definitive target' for DBS in Tourette's syndrome has yet to be determined as the exact neuronal circuitry responsible for symptoms and comorbidities: no animal models for Tourette's syndrome have been realized to date [Jankovic, 2001; Mink et al., 2006]. Due to the wide interpatient variability in the symptoms and comorbidities of Tourette's syndrome, it is probably more appropriate to consider multiple potential targets for DBS with specific target selection based on the clinical characteristics and symptoms in the individual patient.

One of the most commonly used targets for DBS in the treatment of Tourette's syndrome, the centromedianparafascicular complex (CM-Pf), part of the intralaminar nucleus of the thalamus, is involved in sensorimotor basal ganglia circuitry [Krauss et al., 2001; Houeto et al., 2005]. The anterior CM-Pf is able to influence cells involved in tremor generation located in a wide area including the ventral oral anterior and posterior (VoA and $\mathrm{VoP}$ ) nuclei [Katayama et al., 2005]. The intralaminar nuclei and CM-Pf convey multimodal stimulatory signals to the striatum, and are thus involved in attention and arousal in response to stimulation. Stimulation of the CM-Pf and VoA complex has proved to be effective in the treatment of behavioral aspects of Tourette's syndrome as well as alleviation of tics [Servello et al., 2008]. In a study of 18 patients reported by our center treated with DBS of the CM-Pf and VoA, all patients responded well with significant, although varied, reductions in severity and frequency of tics and in behavioral comorbidities after DBS [Servello et al., 2008]. The mean total Yale Global Tic Severity Scale (YGTSS) scores were reduced from $41.1 \pm$ 8.3 prior to DBS to $28.6 \pm 17.5$ post-DBS $(\mathrm{p}<0.001)$ and similar reductions were seen in YGTSS motor, phonic, and social impairment scores (all $\mathrm{p}<0.001$ vs. baseline) [Servello et al., 2008]. In a recent case report, a woman with severe refractory Tourette's syndrome despite DBS of the anterior internal capsule achieved significant improvement in tic control at 3 months following bilateral centromedian thalamic stimulation (reduction in total tic score: $42 \%$ compared with pre-DBS baseline and $27 \%$ compared with DBS of the postinternal capsule) and a reduction in psychiatric side effects such as altered mood and impulse control compared with internal capsule stimulation [Shields et al., 2008].

Although the CM-Pf is often thought to be the preferred target for DBS [Houeto et al., 2005; Servello et al., 2008], alternative locations such as the nucleus accumbens and the GPi are not to be excluded; favorable outcomes in patients with Tourette's syndrome have been reported with DBS of both the nucleus accumbens and the GPi [Vandewalle et al., 1999; Van der Linden et al., 2002; Visser-Vandewalle et al., 2003; Diederich et al., 2005; Flaherty et al., 2005; Houeto et al., 2005; Ackermans et al., 2006; Kuhn et al., 2007; Shahed et al., 2007; Welter et al., 2008].

The anteromedial part of the GPi acts as a limbic relay for output pathways of the basal ganglia, and continuous high frequency stimulation of this region has been shown to ameliorate dystonia [Benabid et al., 1998; Pralong et al., 2003; Bittar et al., 2005; Vidailhet et al., 2005; Hamani and Moro, 2007]. Stimulation of the GPi is able to modify the neuronal activity of the VoA nucleus [Hassler and Dieckmann, 1970; Pralong et al., 2003]. The VoA nucleus is involved in initiating planned movement and suppressing unwanted movement, whereas the VoP nucleus plays a role in the sensations of touch, itching, temperature, taste and arousal, in addition to body position. Recently, in a double-blind, randomized study in 3 patients with severe, refractory Tourette's syndrome, bilateral stimulation of the GPi produced a significant and greater reduction in tic severity (assessed using the YGTSS) than stimulation of the CM-Pf [Welter et al., 2008].

The nucleus accumbens is presumed to have a modulatory activity on amygdaloid basal ganglia-prefrontal cortex circuitry and, as the activity of its neurons is modulated by dopamine and a high proportion of cells have high concentrations of dopamine $\mathrm{D}_{1}$ and $\mathrm{D}_{3}$ receptors, the nucleus accumbens is believed to also be involved in addiction and OCB [Sturm et al., 2003]. The effectiveness of DBS of the nucleus accumbens has been demonstrated in patients with severe OCB and anxiety disorder [Sturm et al., 2003]. In a 37-year-old woman with severe refractory Tourette's syndrome, DBS administered to the anterior limb of the internal capsule (electrode terminating in the nucleus accumbens) provided significant reduction in tic frequency and severity at 18 months after surgery [Flaherty et al., 2005]. Tic reduction was also shown following DBS of the nucleus accumbens in a 26 -year-old male patient with severe tics and SIB; coprolalia and tics 
involving self-harm were almost completely resolved [Kuhn et al., 2007].

The optimal area for the final DBS electrode implantation within the chosen target nucleus was studied with intraoperative microrecordings in at least two monopolar electrode tracks, acquired at steps of 1-0.5 mm from 8-10 $\mathrm{mm}$ above to $1 \mathrm{~mm}$ below the neuroradiologically estimated position of the target nucleus. Undergoing studies are evaluating firing patterns in order to characterize a neurophysiological target thus increasing DBS precision.

\section{Postoperative Evaluation}

The TSA recommends complete neurological, psychiatric and neurophysiological evaluations, including a comparison between pre- and postoperative magnetic resonance imaging (MRI) to assess the correct location of the definitive lead. However, Visser-Vandewalle [2007] suggests that MRI should not be used after surgery as it may produce unwanted effects and that computed tomography scanning should be used instead. In our experience, computed tomography is useful immediately postoperatively to exclude hemorrhagic complications and gross errors in lead positioning, while a comparison between planning and postoperative MRI is routinely performed without observed side effects.

In our protocols, efficacy and safety assessments are performed at several weeks after surgery to allow time for stimulator setting to be optimized and stabilized [according to Mink et al., 2006], and include evaluation of tics using YGTSS and the Modified Rush Video Rating Scale (MRVRS) [Leckman et al., 1989]. Comorbid behavioral symptoms are assessed with the YBOCS for OCB [Goodman et al., 1989a, b), diagnostic criteria of DSMIV-TR for ADHD, the State Trait Anxiety Inventory for anxiety [Bertolotti et al., 1987], the Beck Depression Inventory for depression [Beck et al., 1987], while a tenpoint Visual Analogue Scale (VAS) is considered sufficient for the patient to grade the extent of impairment in social functioning he considers the result of Tourette's syndrome [de Boer et al., 2004].

\section{Use of General Anesthesia}

The nature of behavioral comorbidities often associated with Tourette's syndrome can limit the patient's tolerance towards the length of time and immobilization required for DBS, and a general anesthesia procedure would address these issues. According to Vandewalle et al. [1999], however, general anesthesia precludes the ability to do intraoperative interrogation of the patient to determine the effective electrode position [Visser-Vandewalle, 2007].
Local anesthesia and sedation are often sufficient and preferred as they allows patients' sensations to be evaluated, particularly with regard to avoiding areas which stimulate adverse sensations, while avoiding discomfort caused by the stimulation itself [Visser-Vandewalle, 2007]. Local anesthesia also permits the impact of premonitory sensation on tic genesis to be evaluated. In our experience, after the first 8 cases performed with local anesthesia in order to assess intraoperative safety of the DBS procedure, and better evaluate clinical picture modifications in response to macrostimulation and a putative lesional effect, we decided to perform the DBS procedure under general anesthesia. This was mainly because (1) there were no ascertained examination protocols or expected adverse events reported clearly in the literature to be evaluated with an awake patient, (2) some of the patients exhibited tics of the neck that could possibly lead to self-injury or adjunctive pain due to interference with the stereotactic apparatus, and (3) patients were complaining of the duration of the DBS procedure and the discomfort caused by the frame and the prolonged immobilization.

\section{Postoperative Issues: Adverse Events and Stimulator Adjustment}

DBS is well tolerated in patients with Parkinson's disease and dystonia. Age has been suggested as a factor influencing the difference in DBS tolerability between Tourette's syndrome and Parkinson's disease or dystonia since Parkinson's disease is more common in the elderly; however, this is unlikely given that dystonia is also common in younger patients.

In contrast to Parkinson's disease and dystonia in which the motor component is dominant, Tourette's syndrome presents unique challenges due to the powerful sensory feedback and the compulsive behavioral comorbidities. In our clinic, 2 of 18 patients treated with DBS displayed adverse effects associated with repetitive touching and scratching of the scalp wound or of the area where the pulse generator was positioned [Servello et al., 2008]. Such complications have appeared only in patients with a Tourette's syndrome-plus classification [Robertson and Baron-Cohen, 1998], and were severe enough to require plastic surgery to repair the skin [Servello et al., 2008].

Other adverse effects reported after DBS in patients with Tourette's syndrome include vertical gaze palsy in 1 patient [Ackermans et al., 2007] and dissociation in another [Goethals et al., 2008]. No reports of intracranial hemorrhages have been made to date. 
Although a monthly check for optimization of the setting following DBS is accepted for the vast majority of movement disorders, in our experience a more elastic scheduled timing for Tourette's syndrome patients is required because of the great interpatient variability concerning response to treatment, fluctuations in symptoms and patients' expectations: some patients require more frequent adjustments in order to achieve stable optimal settings. Despite clinical improvement determined by videotaping using the MRVRS [Goetz et al., 1999] and use of neurological scales such as the YGTSS, in younger patients (age $<30$ years) a greater trend towards dysregulation was noted in 7 of the 18 patients treated with DBS and followed for 6 months or more in our earlier study [Servello et al., 2008]. These patients required a more frequent adjustment of stimulator settings after surgery. The cause of this interpatient variation is not clear, but the trend towards an association between more frequent dysregulations and a younger age would appear to present an argument for delaying initiation of DBS in younger patients. It should nevertheless be noted that the prevalence and severity of tics and the behavioral and emotional comorbidities observed in Tourette's syndrome are both higher in younger patients [Leckman et al., 2006; Chang et al., 2008] and so this population could be deemed more likely to benefit from DBS. Furthermore, tics and comorbidities in young people with Tourette's syndrome have a strong association with social impairment expressed as work/school disability and social stigma [Ohm, 2006].

\section{Patients' Expectations versus Realistic Outcomes}

Unfavorable opinions on the outcome of DBS treatment have been reported by 2 of our series of 36 patients (5.5\%) despite statistically significant improvement in the evaluation scales. In our opinion, these negative judgments stem from excessive expectations regarding the magnitude of treatment effect.

A similar lack of satisfaction has also been reported after DBS in patients with Parkinson's disease despite clinical improvement [Tir et al., 2007]. Not only patients' expectations are at the base of their satisfaction, but the caregivers' opinion may influence the judgment of the stimulation effect in the patients as well. There is, for example, the case of a 36-year-old patient driven to continuous modifications of the stimulating parameters by her mother, as she was not satisfied with the results achieved by her daughter after DBS.

Deep Brain Stimulation for Refractory

Tourette's Syndrome
Furthermore, patients tend to perceive normal fluctuations in their symptoms - even if much less disabling than in the preoperative period - with somewhat greater discomfort, interpreting a brief and transient decrease in treatment results as an unsuccessful result of DBS. It has to be made clear to the patients specifically that the usual fluctuation of symptoms related to natural history of Tourette's syndrome is likely to continue after DBS.

Experience has led us to put greater stress on realistic expectations and previsions of results of DBS of the patient and caregivers during preoperative assessments. On the other hand, we felt the need for a more objective and detached method for the assessment of the results of DBS during the follow-up endpoints with instruments such as YGTSS and videotaping. Finally, psychological support should be provided in cases in which strong behavioral comorbidity is documented preoperatively.

\section{Feasibility of Deep Brain Stimulation in the Clinical Setting}

Despite considerable issues and limitations, DBS is an effective procedure for treatment-refractory Tourette's syndrome patients that exhibit a significant social impairment directly related to the clinical picture. Therefore, DBS is in our opinion to be considered as an add-on measure over conservative pharmacological, behavioral and invasive nonsurgical maneuvers when tic severity and social impairment are high: our guidelines state a cutoff at a total YGTSS score $\geq 49$, with a YGTSS social impairment subitem $>30$.

It has nevertheless become evident in our experience that YGTSS does not accurately describe the importance of comorbidities and the degree of social impairment and may be inadequate as a criterion for inclusion in a surgical trial. Similarly, videotaping must now be considered insufficient for the evaluation of patients with Tourette's syndrome as potential candidates for surgery, and should no longer be used as a determining criterion for inclusion in a surgical trial. Logical next steps for the evaluation of patients with Tourette's syndrome for DBS include defining the characteristics of the candidate patients.

In our opinion, comorbidities should be included in the definition of the clinical picture of Tourette's syndrome as a determining factor for DBS rather than a secondary feature: for this reason, in addition to YGTSS and videotaping, full evaluation for DBS suitability should include the patient's subjective assessment of illness evalu-

Eur Neurol 2009;62:264-273 
ated by a ten-point VAS and a psychological interview to evaluate behavioral symptoms.

In a disease as complex as Tourette's syndrome, the importance of a dedicated center with an experienced multidisciplinary team to achieve optimal outcomes with DBS cannot be overstated. The functional neurosurgeon, the neurologist and the psychologist should all collaborate closely in the decision-making process ranging from the appropriate selection of patients to the choice of conservative treatment or surgery.

\section{Conclusion}

DBS surgery is associated with a low risk of complications and is generally well tolerated by patients and caregivers and, therefore, appears promising as a viable treatment option for Tourette's syndrome; however, there are numerous issues still to be resolved. The selection of precise targets for DBS is mandatory and may require the delineation of different subtypes of Tourette's syndrome. Our clinical data show DBS at the Vo-CM-Pf to be an effective treatment for severe and refractory Tourette's syndrome, producing durable improvements (up to 2 years) in tics, comorbidities, quality of life and medication requirements. Other targets such as the nucleus accumbens and the GPi also show clinical promise. Studies of DBS in
Tourette's syndrome have involved only small numbers of patients to date and further research is needed to refine these observations.

Establishment of consistent inclusion criteria and recognition of specific requirements for each surgical/medical center are essential to improve clinical outcomes and consistency of surgical trials in patients with Tourette's syndrome. Clinical studies are required to improve evaluation of non-tic symptoms and investigate the adoption of detailed neurophysiological parameters during surgery with the aim of identifying the optimum neurophysiological target in place of clinical and neuroradiological targets used currently.

It is important to note that DBS is not an alternative treatment for Tourette's syndrome, but rather an add-on therapy for those who fail to respond to conservative medical and psychological and invasive nonsurgical (such as botulinum toxin infiltration) treatments. A multidisciplinary team with experience in all these treatment modalities as well as in DBS is, therefore, mandatory.

\section{Acknowledgements}

Medical writing assistance was provided by Raewyn Poole and Mary Hines, Wolters Kluwer Health.

We would also like to acknowledge Ms. Olga Lee Rachello for English supervision and translation.

\section{References}

Ackermans L, Temel Y, et al: Deep brain stimulation in Tourette's syndrome: two targets? Mov Disord 2006;21:709-713.

-Ackermans L, Temel Y, et al: Vertical gaze palsy after thalamic stimulation for Tourette syndrome: case report. Neurosurgery 2007;61: E1100.

- Bajwa RJ, de Lotbiniere AJ, et al: Deep brain stimulation in Tourette's syndrome. Mov Disord 2007;22:1346-1350.

Beck AT, Rush AI, Shaw BF, Emery G: Terapia cognitiva della depressione. Turin, Boringhieri, 1987.

- Benabid AL, Benazzouz A, et al: Long-term electrical inhibition of deep brain targets in movement disorders. Mov Disord 1998; 13(suppl 3):119-125.

Bertolotti G, Michelin P, et al: CBA 2.0 Cognitive Behavioural Assessment, ed 4. Florence, Organizzazioni Speciali, 1987.

- Bittar RG, Yianni J, et al: Deep brain stimulation for generalised dystonia and spasmodic torticollis. J Clin Neurosci 2005;12:12-16.
Chang HL, Liang HY, et al: Behavioral and emotional problems in adolescents with Tourette syndrome. Chang Gung Med J 2008;31:145152.

de Boer AG, van Lanschot JJ, et al: Is a singleitem visual analogic scale as valid, reliable and responsive as multi-item scales in measuring quality of life? Qual Life Res 2004;13: 311-320.

Dehning S, Mehrkens JH, et al: Therapy-refractory Tourette syndrome: beneficial outcome with globus pallidus internus deep brain stimulation. Mov Disord 2008;23:1300-1302.

-Deuschl G, Schade-Brittinger C, et al: A randomized trial of deep-brain stimulation for Parkinson's disease. N Engl J Med 2006;355: 896-908.

Diederich NJ, Kalteis K, et al: Efficient internal pallidal stimulation in Gilles de la Tourette syndrome: a case report. Mov Disord 2005; 20:1496-1499.

DSM-IV-TR: Diagnostic and Statistical Manual of Mental Disorders, 4th Edition. Washington, American Psychiatric Association, 2000, pp 111-114.
Flaherty AW, Williams ZM, et al: Deep brain stimulation of the anterior internal capsule for the treatment of Tourette syndrome: technical case report. Neurosurgery 2005; 57(suppl 4):E403.

Freeman RD, Fast DK, et al: An international perspective on Tourette syndrome: selected findings from 3,500 individuals in 22 countries. Dev Med Child Neurol 2000;42:436447.

Gallagher CL, Garell PC, et al: Hemi tics and deep brain stimulation. Neurology 2006;66:E12.

Goodman WK, Price LH, Rasmussen SA: The Yale-Brown Obsessive Compulsive Scale. I. Development, use, and reliability. Arch Gen Psychiatry 1989a;46:1006-1011.

Goodman WK, Price LH, Rasmussen SA: The Yale-Brown Obsessive Compulsive Scale. II. Validity. Arch Gen Psychiatry 1989b;46: 1012-1016.

Goethals I, Jacobs F, et al: Brain activation associated with deep brain stimulation causing dissociation in a patient with Tourette's syndrome. J Trauma Dissociation 2008;9:543549 . 
Goetz CG, Pappert EJ, et al: Advantages of a modified scoring method for the Rush Video-Based Tic Rating Scale. Mov Disord 1999; 14:502-506.

Halpern C, Hurtig H, et al: Deep brain stimulation in neurologic disorders. Parkinsonism Relat Disord 2007;13: 1-16.

-Hamani C, Moro E: Surgery for other movement disorders: dystonia, tics. Curr Opin Neurol 2007;20:470-476.

-Hassler R, Dieckmann G: Stereotaxic treatment of tics and inarticulate cries or coprolalia considered as motor obsessional phenomena in Gilles de la Tourette's disease. Rev Neurol (Paris) 1970;123:89-100.

-Houeto JL, Karachi C, et al: Tourette's syndrome and deep brain stimulation. J Neurol Neurosurg Psychiatry 2005;76:992-995.

ICD-10 International Classification of Disease and Related Health Problems, 10th Edition: classification of mental and behavioural disorders: clinical descriptions and diagnostic guidelines. Geneva, World Health Organization, 1992, pp 284-286.

-Jankovic J: Tourette syndrome. Phenomenology and classification of tics. Neurol Clin 1997; 15:267-275.

Jankovic J: Tourette's syndrome. N Engl J Med 2001;345:1184-1192.

Katayama Y, Kano T, et al: Difference in surgical strategies between thalamotomy and thalamic deep brain stimulation for tremor control. J Neurol 2005;252(suppl 4):IV17-IV22.

Krack P, Batir A, et al: Five-year follow-up of bilateral stimulation of the subthalamic nucleus in advanced Parkinson's disease. N Engl J Med 2003;349:1925-1934.

-Krauss JK, Simpson RK Jr, et al: Concepts and methods in chronic thalamic stimulation for treatment of tremor: technique and application. Neurosurgery 2001;48:535-543.

Kuhn, J, Lenartz D, et al: Deep brain stimulation of the nucleus accumbens and the internal capsule in therapeutically refractory Tourette-syndrome. J Neurol 2007;254:963965.

Leckman JF: Tourette's syndrome. Lancet 2002; 360:1577-1586.

Leckman JF, Bloch MH, et al: Tourette syndrome: the self under siege. J Child Neurol 2006;21:642-649.

Leckman JF, Riddle MA, Hardin MT: The Yale Global Tic Severity Scale: initial testing of a clinician-rated scale of severity. Am Acad Child Adolesc Psychiatry 1989;28:566-573.

Leckman JF, Zhang H, et al: Course of tic severity in Tourette syndrome: the first two decades. Pediatrics 1998;102:14-19.

Machado A, Rezai AR, et al: Deep brain stimulation for Parkinson's disease: surgical technique and perioperative management. Mov Disord 2006;21(suppl 14):S247-S258.
Maciunas RJ, Maddux BN, et al: Prospective randomized double-blind trial of bilateral thalamic deep brain stimulation in adults with Tourette syndrome. J Neurosurg 2007;107: 1004-1014.

Mason A, Banerjee S, et al: The prevalence of Tourette syndrome in a mainstream school population. Dev Med Child Neurol 1998;40: 292-296.

Mink JW, Walkup J, et al: Patient selection and assessment recommendations for deep brain stimulation in Tourette syndrome. Mov Disord 2006;21:1831-1838.

Nogueira Rivero G: The Machover test: diagnostic and therapeutic importance in an 11year-old girl with an obsessive neurosis. Rev Cubana Pediatr 1960;32:581-590.

$\checkmark$ Ohm B: The effect of Tourette syndrome on the education and social interactions of a schoolage child. J Neurosci Nurs 2006;38:194-195, 199.

Orth M, Kirby R, et al: Subthreshold rTMS over pre-motor cortex has no effect on tics in patients with Gilles de la Tourette syndrome. Clin Neurophysiol 2005;116:764-768.

Packer LE: Social and educational resources for patients with Tourette syndrome. Neurol Clin 1997; 15:457-473.

Peterson BS, Skudlarski P, et al: A functional magnetic resonance imaging study of tic suppression in Tourette syndrome. Arch Gen Psychiatry 1998;55:326-333.

Porta M, Maggioni GR, Ottaviani F, Schindler A: Treatment of phonic tics in patients with Tourette's syndrome using botulinum toxin type A. Neurol Sci 2003;24:420-423.

Porta M, Sassi M, et al: Tourette's syndrome and role of tetrabenazine: review and personal experience. Clin Drug Investig 2008;28: 443-459.

Porta M, Servello D, et al: Advances in Gilles de la Tourette syndrome: preliminary results in a cohort of 10 patients treated with DBS; in van Hilten B, Nuttin B (eds): Proceedings of the Medtronic Forum for Neuroscience and Neuro-Technology 2005. Part III. Berlin, Springer, 2005.

Pralong E, Debatisse D, et al: Effect of deep brain stimulation of GPI on neuronal activity of the thalamic nucleus ventralis oralis in a dystonic patient. Neurophysiol Clin 2003;33: 169-173.

Robertson MM: Tourette syndrome, associated conditions and the complexities of treatment. Brain 2000;123:425-462.

Robertson MM, Baron-Cohen S: Tourette Syndrome: the Facts. London, Oxford University Press, 1998.
Servello D, Porta M, et al: Deep brain stimulation in 18 patients with severe Gilles de la Tourette syndrome refractory to treatment: the surgery and stimulation. J Neurol Neurosurg Psychiatry 2008;79:136-142.

Shahed J, Poysky J, et al: GPi deep brain stimulation for Tourette syndrome improves tics and psychiatric comorbidities. Neurology 2007;68:159-160.

Shields DC, Cheng ML, et al: Microelectrodeguided deep brain stimulation for Tourette syndrome: within-subject comparison of different stimulation sites. Stereotact Funct Neurosurg 2008;86:87-91.

Singer HS, Minzer K: Neurobiology of Tourette's syndrome: concepts of neuroanatomic localization and neurochemical abnormalities. Brain Dev 2003;25(suppl 1):S70-S84.

Sturm V, Lenartz D, et al: The nucleus accumbens: a target for deep brain stimulation in obsessive-compulsive- and anxiety-disorders. J Chem Neuroanat 2003;26:293-299.

TSCS Group: Definitions and classification of tic disorders. The Tourette Syndrome Classification Study Group. Arch Neurol 1993;50: 1013-1016.

Tir M, Devos D, et al: Exhaustive, one-year follow-up of subthalamic nucleus deep brain stimulation in a large, single-center cohort of parkinsonian patients. Neurosurgery 2007; 61:297-305.

Van der Linden C, Colle H, et al: Successful treatment of tics with bilateral internal pallidum (GPi) stimulation in a 27-year-old male patient with Gilles de la Tourette's syndrome (GTS). Mov Disord 2002;17(suppl 5): P1130.

-Vandewalle V, van der Linden C, et al: Stereotactic treatment of Gilles de la Tourette syndrome by high frequency stimulation of thalamus. Lancet 1999;353:724.

Vidailhet M, Vercueil L, et al: Bilateral deepbrain stimulation of the globus pallidus in primary generalized dystonia. N Engl J Med 2005;352:459-467.

-Visser-Vandewalle V: DBS in Tourette syndrome: rationale, current status and future prospects. Acta Neurochir Suppl 2007;97: 215-222.

Visser-Vandewalle V, Temel Y, et al: Chronic bilateral thalamic stimulation: a new therapeutic approach in intractable Tourette syndrome. Report of three cases. J Neurosurg 2003;99:1094-1100.

Welter ML, Mallet L, et al: Internal pallidal and thalamic stimulation in patients with Tourette syndrome. Arch Neurol 2008;65:952957.

Woods DW, Piacentini J, et al: Premonitory Urge for Tics Scale (PUTS): initial psychometric results and examination of the premonitory urge phenomenon in youths with tic disorders. J Dev Behav Pediatr 2005;26:397-403. 


\section{Erratum}

The following authors' corrections were added after print to the paper by Porta et al: Issues related to deep brain stimulation for treatment-refractory Tourette's syndrome. Eur Neurol 2009;62:264-273, please amend:

p. 264: second author's name was misspelled, should now read 'Domenico Servello'; p. 269 line 17 column 2: substitute 'anteromedial' with 'posteroventral';

p. 269 line 17 column 2: substitute 'lymbic' with 'sensorimotor';

p. 269 line 31 column 2: substitute 'Gpi' with 'anteromedial Gpi';

p. 270 line 47 column 2: substitute 'No' with 'One';

p. 270 line 48 column 2: add '[Diederich et al, 2005]'. 